\title{
Pulmonary Artery Banding for Neonates and Early Infants with Low Body Weight
}

\author{
Mitsugi Nagashima, ${ }^{1}$ Toru Okamura, ${ }^{1}$ Fumiaki Shikata, ${ }^{1}$ Toshiyuki Chisaka, ${ }^{2}$ \\ Hidemi Takata, ${ }^{2}$ Masaaki Ohta, ${ }^{2}$ Eiichi Yamamoto ${ }^{2}$ and Takashi Higaki ${ }^{2}$ \\ ${ }^{1}$ Department of Surgery, Division of Pediatric Cardiovascular Surgery, Ehime University School of Medicine, \\ Ehime, Japan \\ ${ }^{2}$ Department of Pediatrics, Ehime University School of Medicine, Ehime, Japan
}

\begin{abstract}
Open heart surgery for infants with low body weight (BW) remains still a challenge. Pulmonary artery banding (PAB) is a useful surgical palliation for small neonates and early infants with excessive pulmonary blood flow who are unable to withstand a heart surgery. This study retrospectively reviewed neonates and infants who underwent PAB to assess the surgical results and the validity of our PAB. We selected 38 acyanotic infants and neonates and divided them into 2 groups: low BW $(<2.5 \mathrm{~kg}, n=15$, group $\mathrm{L})$ and normal or high BW $(\geq 2.5 \mathrm{~kg}, n=23$, group $\mathrm{NH})$. The average BW at the time of PAB was $2.8 \pm 1.1 \mathrm{~kg}$ (range, 1.2-5.8 kg), and the average age at the time of PAB was $41.8 \pm 44.8$ days (range, 2-151 days). Using a 3-mm-wide polyester tape, we tightened the main pulmonary artery to obtain the circumference of $(19 \mathrm{~mm}+1 \mathrm{~mm}$ for each $\mathrm{kg}$ of BW). There was no early death but one late death in each group. Postoperative BW continuously increased 1 month after PAB in both groups, although BW was significantly lower in group $L$ than in group $\mathrm{NH}$. Intracardiac repair (ICR) was accomplished in 31 patients (13 in group $L$ and 18 in group $\mathrm{NH}$ ) at average ages of 1.5 years, while the remaining 5 patients are awaiting ICR. In conclusion, PAB using our formula for the infants even weighing $<2.5 \mathrm{~kg}$ has low mortality and is effective as a bridge to ICR.
\end{abstract}

Keywords: infant; low birth weight; neonate; palliative surgery; pulmonary artery banding Tohoku J. Exp. Med., 2011, 225 (4), 255-262. (C) 2011 Tohoku University Medical Press

In neonates and early infants with low body weight (BW), cardiopulmonary bypass surgery increases organ edema and dysfunction, leading to high mortality and morbidity (Oppido et al. 2004). Pulmonary artery banding $(\mathrm{PAB})$ remains a useful surgical palliation for small neonates and early infants with excessive pulmonary blood flow who are unable or difficult to withstand an open heart surgery using cardiopulmonary bypass. PAB can relieve the symptoms of heart failure and respiratory distress and prevent future pulmonary vascular obstructive disease in these infants and intracardiac repair (ICR) can be delayed until they grow. Trusler and Mustard (1972) advocated that the adequate circumference of the PAB using a 4-mm-wide tape in infants without cyanosis was $(20 \mathrm{~mm}+1 \mathrm{~mm}$ for each $\mathrm{kg}$ of the infant BW). The Trusler's formula has been used as a standard for PAB in pediatric cardiac surgery field for a long period. However, the average birth $\mathrm{BW}$ in the Japan is lower than in the United States and European countries and per se decreased in the recent years. A wider tape for PAB may cause the distal PA stenosis in small neonates and infants. In addition, the average $\mathrm{BW}$ in our PAB series was much lower than that reported previously. Therefore, in our institution, we have routinely used a 3-mm-wide tape (1 mm narrower than Trusler's group) and our modified formula (19 mm $+1 \mathrm{~mm}$ for each $\mathrm{kg}$ of BW), $1 \mathrm{~mm}$ shorter circumference than Trusler's formula] had been applied to obtain the appropriate PAB circumference (Fig. 1). Accordingly, the present study retrospectively reviewed patients who underwent $\mathrm{PAB}$ to investigate the surgical results and to assess the validity of our modified formula, particularly for small infants and neonates weighing less than $2.5 \mathrm{~kg}$ at the time of PAB.

\section{Methods}

From 2000 through 2009, 38 acyanotic infants and neonates who had excessive pulmonary blood flow and who were suitable for subsequent biventricular repair underwent PAB. The average gestational age was $37.3 \pm 2.1$ weeks (range, 32-40 weeks), the average BW at the time of PAB was $2.8 \pm 1.1 \mathrm{~kg}$ (range, 1.2-5.8 kg), and the average age at the time of PAB was $41.8 \pm 44.8$ days (range, 2-151 days). These patients were divided into 2 groups according to the $\mathrm{BW}$ at the time of PAB: low BW (less than $2.5 \mathrm{~kg}, n=15$, group L)

Received June 7, 2011; revision accepted for publication October 29, 2011. doi: 10.1620/tjem.225.255

Correspondence: Mitsugi Nagashima, M.D., Department of Surgery, Division of Pediatric Cardiovascular Surgery, Ehime University School of Medicine, Shitsukawa, Toon City, Ehime 791-0295, Japan.

e-mail: mitsugi@aqua.plala.or.jp or mitsugi@m.ehime-u.ac.jp 
Trusler's formula

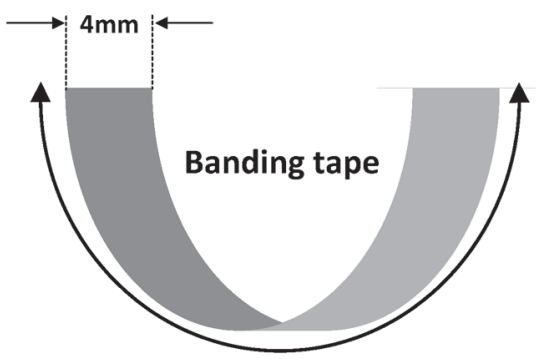

$20 \mathrm{~mm}+1 \mathrm{~mm}$ for each $\mathrm{kg}$ of BW

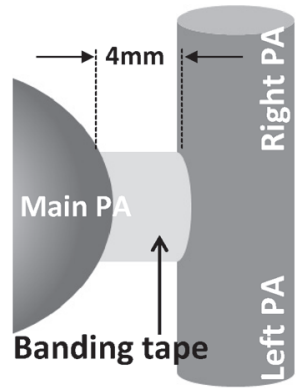

Pulmonary artery

\section{Our modified Trusler's formula}

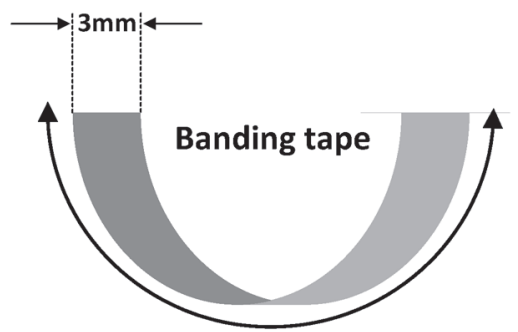

$19 \mathrm{~mm}+1 \mathrm{~mm}$ for each $\mathrm{kg}$ of BW

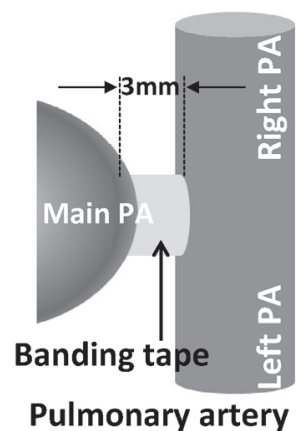

Fig. 1. Schema of pulmonary artery banding according to Trusler's formula or our modified Trusler' formula. The main pulmonary artery is banded at a point just proximal of the bifurcation of both right and left pulmonary artery. Our modified formula bands the main pulmonary artery by $1 \mathrm{~mm}$ tighter circumference with a 1-mm narrower tape compared with original Trusler's formula. If BW of an infant is $3 \mathrm{~kg}$, the appropriate circumference of $\mathrm{PAB}$ is $23 \mathrm{~mm}$ according to Trusler's formula and $22 \mathrm{~mm}$ according to our modified formula. PA, pulmonary artery.

and normal or high $\mathrm{BW}(\geq 2.5 \mathrm{~kg}, n=23$, group $\mathrm{NH})$. The indications for PAB in our institution were as follows: all cases of coarctation of the aorta (CoA) or type A interruption of the aortic arch (IAA) complex; simple VSD with BW less than $3 \mathrm{~kg}$; and apical muscular and/or multiple VSDs or atrioventricular septal defects with BW less than $5 \mathrm{~kg}$. The characteristics of the patient population and anatomical diagnosis are summarized in Table 1.

\section{Anesthesia and operative technique}

Fentanyl and midazolam were administered to induce and maintain anesthesia, and vecuronium bromide or rocuronium bromide was intermittently used as a muscle relaxant. The operation was performed via left thoracotomy with a posterolateral small skin incision. In cases that required associated procedures, patent ductus arteriosus ligation or division, or CoA/IAA repair (end-to-end anastomosis in the majority of cases) was performed. Polyester tape ( $3 \mathrm{~mm}$ in width) was used as the banding tape, and the main pulmonary artery (PA) was tightened according to the modified Trusler's formula (19 mm + $1 \mathrm{~mm}$ for each $\mathrm{kg}$ of BW) that was used in our institution. Artificial ventilation was maintained using a fraction of inspired oxygen of $40 \%$ at $15-20$ min before the main PA was banded. Appropriate tightening of the band was judged if systemic pressure increased by 10-20 $\mathrm{mm} \mathrm{Hg}$ and good thrill was palpable on the band. If these conditions were not observed, the pressure of the distal PA was measured and adjusted to a mean PA pressure of less than 20-25 mm Hg. Moreover, if arterial oxygen saturation could not be maintained above $90 \%$, the banding tape was loosened. To prevent migration of the tape, three 5-0 polypropylene stitches were placed on the adventitia of the main
PA at the proximal and distal sites of the banding tape.

\section{Postoperative care}

The peak velocity (PV) at the banding site was episodically measured by transthoracic echocardiography immediately after the operation; 1 week after the operation; and at 1, 3, 6, and 12 months after the operation when possible. BW was also measured at 1 week and 1,3, 6, and 12 months after PAB and expressed as a percent of the normal value to assess the degree of growth. In premature infants, BW was corrected for gestational age. In patients with trisomy 21, BW was also expressed as a percent of the average BW of Japanese patients with trisomy 21 (Kuroki, 1985). Usually, ICR was planned when the BW of the patients exceeded $6-8 \mathrm{~kg}$ because many patients could undergo ICR without autologous blood transfusion at these BWs. When migration of the banding tape, oxygen desaturation, or regression of the BW gain was recognized in the outpatient, ICR was hastened. Before ICR, cardiac catheterization was usually performed to assess the pulmonary arterial pressure, pulmonary to systemic flow ratio, and pulmonary vascular resistance. This study was approved by the ethics committee of our institute. Data are presented as the mean \pm standard deviation, and the range with median is provided in the parentheses. We tested for differences between groups by using the unpaired Student's $t$-test or repeated-measures analysis of variance. Frequency data were compared using the $\chi^{2}$ or Fisher's exact test. A $p$-value below 0.05 was considered significant. 
Table 1. Patient characteristics at PAB and surgical outcomes.

\begin{tabular}{|c|c|c|c|}
\hline & $\begin{array}{l}\text { Group L } \\
(n=15)\end{array}$ & $\begin{array}{c}\text { Group NH } \\
(n=23)\end{array}$ & $p$-value \\
\hline Gestational age at birth (week) & $\begin{array}{c}36.6 \pm 2.3 \\
\text { (range, } 32-39 ; \text { median, 37) }\end{array}$ & $\begin{array}{c}38.2 \pm 1.6 \\
\text { (range, } 37-41 ; \text { median, } 38 \text { ) }\end{array}$ & $<0.05$ \\
\hline Age at PAB (day) & $\begin{array}{c}21.9 \pm 24.4 \\
\text { (range, } 2-54 ; \text { median, } 14 \text { ) }\end{array}$ & $\begin{array}{c}55.5 \pm 50.2 \\
\text { (range, } 4-151 ; \text { median, } 34 \text { ) }\end{array}$ & $<0.01$ \\
\hline $\mathrm{BW}$ at $\mathrm{PAB}(\mathrm{kg})$ & $\begin{array}{c}1.99 \pm 0.39 \\
\text { (range, } 1.2-2.4 ; \text { median, 2.1) }\end{array}$ & $\begin{array}{c}3.32 \pm 0.94 \\
\text { (range, } 2.5-5.8, \text { median 3.0) }\end{array}$ & $<0.001$ \\
\hline \multicolumn{4}{|l|}{ Anatomical diagnosis } \\
\hline VSD & 10 & 10 & \\
\hline VSD w CoA or IAA & 3 & 7 & \\
\hline AVSD & 0 & 2 & \\
\hline AVSD w CoA & 1 & 2 & \\
\hline DORV & 1 & 1 & \\
\hline ACMGA w CoA & 0 & 1 & \\
\hline \multicolumn{4}{|l|}{ Other significant disease } \\
\hline 21 trisomy & 3 & 7 & \\
\hline Esophageal atresia & 2 & 0 & \\
\hline Anal atresia & 1 & 0 & \\
\hline Hydrops fetalis & 2 & 0 & \\
\hline Biliary dilatation & 0 & 1 & \\
\hline Tracheomalacia & 2 & 0 & \\
\hline \multicolumn{4}{|l|}{ Concomitant procedure at $\mathrm{PAB}$} \\
\hline $\mathrm{CoA} / \mathrm{IAA}$ repair & 4 & 10 & \\
\hline PDA ligation & 3 & 3 & \\
\hline Mechanical ventilation (days) & $\begin{array}{c}26.8 \pm 42.6 \\
(2-123 ; \text { median, } 6)\end{array}$ & $\begin{array}{c}2.8 \pm 2.2 \\
(0-10 ; \text { median, } 3)\end{array}$ & $<0.05$ \\
\hline Hospitalization (days) & $\begin{array}{c}102 \pm 94 \\
(23-347 ; \text { median, } 74)\end{array}$ & $\begin{array}{c}42 \pm 26 \\
(18-124 ; \text { median, 36) }\end{array}$ & N.S. \\
\hline
\end{tabular}

PAB, pulmonary artery banding; VSD, ventricular septal defect; w CoA or IAA, with coarctation of the aorta or interruption of the aorta; AVSD, atrioventricular septal defect; DORV, double outlet right ventricle; ACMGA, anatomically corrected malposition of the great arteries; PDA, persistent ductus arteriosus. In group $\mathrm{NH}$, the data for mechanical ventilation and hospitalization for the patient who died before discharge were excluded.

\section{Results}

\section{Surgical result}

One patient with a BW of $1.2 \mathrm{~kg}$ in group $\mathrm{L}$ required a band with an $18-\mathrm{mm}$ circumference $(16.8 \mathrm{~mm}+1 \mathrm{~mm}$ for each $\mathrm{kg}$ of BW), $2.2 \mathrm{~mm}$ tighter than the modified formula) to obtain a stable pressure gradient with PAB (Fig. 2). The banding tape was loosened by more than $1.5 \mathrm{~mm}$ compared with the modified formula in 2 patients in group NH. In a 4-month-old patient with an atrioventricular septal defect and $\mathrm{CoA}$, the banding tape was loosened by $1.7 \mathrm{~mm}$ because of hypoxia, and in another patient with multiple VSDs and enlarged PAs, the banding tape was loosened by $2 \mathrm{~mm}$ because of unstable hemodynamics. Two patients from each of the 2 groups, Group L and Group NH, required minor adjustments in the circumference of the banding tape. Therefore, in all patients, except in the above-mentioned 7 patients, the banding tape was tightened in line with the modified formula $(19 \mathrm{~mm}+1 \mathrm{~mm}$ for each $\mathrm{kg}$ of BW) (Fig. 2).
In group L, 1 patient with VSDs died because of parental abuse 4 months after PAB. In group NH, 1 patient who had severe CoA and large VSDs died due to infection and renal failure 10 months after PAB. This patient was transferred to our institution in a state of shock, and prostaglandin administration failed to open the ductus arteriosus. Although emergency end-to-end arch anastomosis with $\mathrm{PAB}$ was performed the same day, renal insufficiency was not alleviated, necessitating peritoneal dialysis until the time of death.

In one patient of group L, the band required retightening by $0.5 \mathrm{~mm}$, and the band was placed in the proper position on the next day after surgery. Another patient in group $\mathrm{NH}$ required a Blalock-Taussig shunt procedure at 1 year and 9 months of age for very hypoplastic PA caused by severe PA stenosis due to migration of the banding tape. The progression of infundibular stenosis or subaortic stenosis was not observed in either group. ICR was hastened because of the regression of the BW gain in 3 patients, of which 1 patient in group $\mathrm{L}$ had esophageal atresia and the 


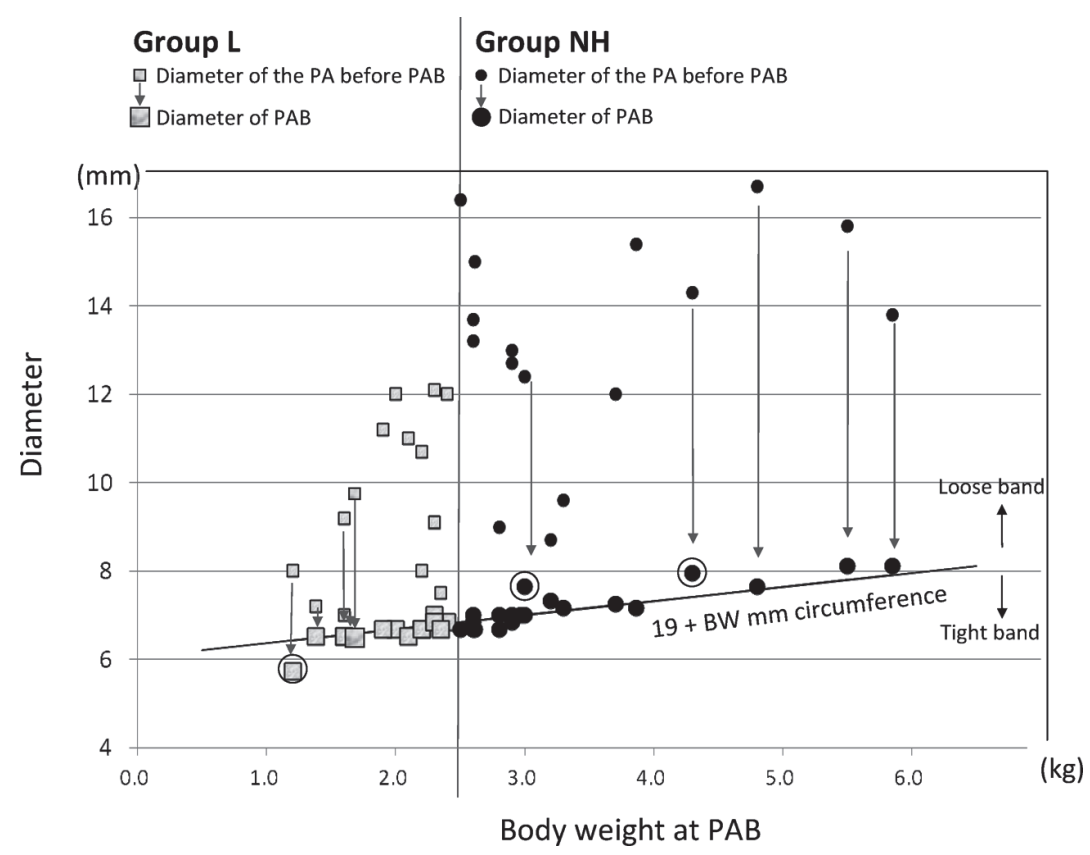

Fig. 2. Diameter of the native main PA before $\mathrm{PAB}$ and the diameter at the site of $\mathrm{PAB}$ relative to $\mathrm{BW}$ at the time of banding. The large black circle shows the diameter of $\mathrm{PAB}$ in group $\mathrm{NH}$, and the large gray square shows the diameter of $\mathrm{PAB}$ in group L. The smaller black circles and gray squares show the diameter of the native main PA before PAB in group NH and group L, respectively. The straight line shows the target banding circumference using the modified Trusler's formula $(19 \mathrm{~mm}+1 \mathrm{~mm}$ for each $\mathrm{kg}$ of BW). The 3 rings represent patients for whom the banding circumference deviated from this modified formula by more or less than $1.5 \mathrm{~mm}$. $\mathrm{PAB}$, pulmonary artery banding; BW, body weight.

Table 2. Catheterization data before ICR.

\begin{tabular}{llcl}
\hline & Group L $(n=13)$ & Group NH $(n=18)$ & $p$-value \\
\hline Catheterization data & & & N.S. \\
Mean right PA (mmHg) & $15.1 \pm 4.7$ & $19.5 \pm 9.0$ & N.S. \\
Mean left PA (mmHg) & $20.1 \pm 6.0$ & $21.7 \pm 5.8$ & N.S. \\
Qp/Qs & $1.22 \pm 0.40$ & $1.42 \pm 0.50$ & N.S. \\
$\mathrm{Rp}$ (Wood units) & $3.1 \pm 1.1$ & $2.6 \pm 1.3$ & N.S. \\
$\mathrm{SaO}_{2}$ (\%) & $93.7 \pm 7.6(77-100)$ & $92.9 \pm 5.7(83-100)$ & N.S. \\
Interval (PAB-Cath) (months) & $14.1 \pm 6.6(2-21)$ & $13.2 \pm 6.4(2-25)$ & \\
\hline
\end{tabular}

ICR, intracardiac repair; PA, pulmonary artery; Qp/Qs, Pulmonary-to-systemic blood flow ratio; Rp, pulmonary vascular resistance; $\mathrm{SaO}_{2}$, arterial oxygen saturation; $\mathrm{PAB}$, pulmonary artery banding; Cath, catheterization.

other 2 in group NH. In one patient of group NH, ICR was hastened because of the progression of supravalvular aortic stenosis. All 4 of these patients underwent ICR in less than 6 months after PAB.

Cardiac catheterization was performed in 31 patients (13 in group L and 18 patients in group $\mathrm{NH}$ ) prior to ICR, and their data are presented in Table 2. In 4 patients in group $\mathrm{L}$ and 3 patients in group $\mathrm{NH}$, the mean pressure was $5 \mathrm{~mm} \mathrm{Hg}$ or more lower in the right PA than in the left PA due to stenosis of the right PA caused by the banding tape. These 31 patients underwent ICR. The remaining 5 patients (1 patients in group $\mathrm{L}$ and 4 patients in group $\mathrm{NH}$ ) are awaiting ICR. The average interval between PAB and ICR is also shown in Table 3. At the time of ICR, when periph- eral PA stenosis due to the banding tape was recognized, a patch augmentation was performed using fresh or glutaraldehyde-treated autologous pericardium, even if there was a small or nonexistent pressure gradient between the right and left PAs at the time of catheterization. The frequency of this procedure at the time of ICR in both groups is also shown in Table 3.

\section{Change in $P V$ at the site of $P A B$}

The PV at the site of PAB, as measured by transthoracic echocardiography, was significantly lower in group $\mathrm{L}$ than in group NH immediately after PAB $(2.9 \pm 0.5 \mathrm{~m} / \mathrm{s}$ in group L vs. $3.5 \pm 0.5 \mathrm{~m} / \mathrm{s}$ in group $\mathrm{NH}, p<0.05)$ and 1 week after PAB $(3.2 \pm 0.4 \mathrm{~m} / \mathrm{s}$ in group L vs. $3.7 \pm 0.5 \mathrm{~m} / \mathrm{s}$ 
Table 3. Miscellaneous data at ICR.

\begin{tabular}{|c|c|c|c|}
\hline & Group L $(n=13)$ & Group NH $(n=18)$ & $p$-value \\
\hline Interval (PAB-ICR) (months) & $\begin{array}{c}17.0 \pm 6.6 \\
\text { (range } 3-26 ; \text { median, } 18 \text { ) }\end{array}$ & $\begin{array}{l}16.6 \pm 9.2 \\
\text { (range } 2-28 ; \text { median, 17) }\end{array}$ & N.S. \\
\hline Age at ICR (months) & $\begin{array}{c}17.7 \pm 7.6 \\
\text { (range } 6-26 ; \text { median, } 19 \text { ) }\end{array}$ & $\begin{array}{c}19.2 \pm 9.9 \\
\text { (range } 4-30 ; \text { median, } 22)\end{array}$ & N.S. \\
\hline BW at ICR (kg) & $\begin{array}{c}7.4 \pm 2.4 \\
\text { (range } 4.0-10.5 ; \text { median, } 7.1 \text { ) }\end{array}$ & $\begin{array}{c}7.9 \pm 2.4 \\
\text { (range } 3.2-10.9 ; \text { median, } 8.0 \text { ) }\end{array}$ & N.S. \\
\hline \multicolumn{4}{|c|}{ Peripheral PA patch augmentation at ICR } \\
\hline Right & 6 & 3 & \\
\hline Left & 1 & 0 & \\
\hline Both sides & 0 & 3 & \\
\hline Total & $7 / 13(54 \%)$ & $6 / 18(33 \%)$ & N.S. \\
\hline
\end{tabular}

ICR, intracardiac repair; PAB, pulmonary artery banding; BW, body weight; PA, pulmonary artery.

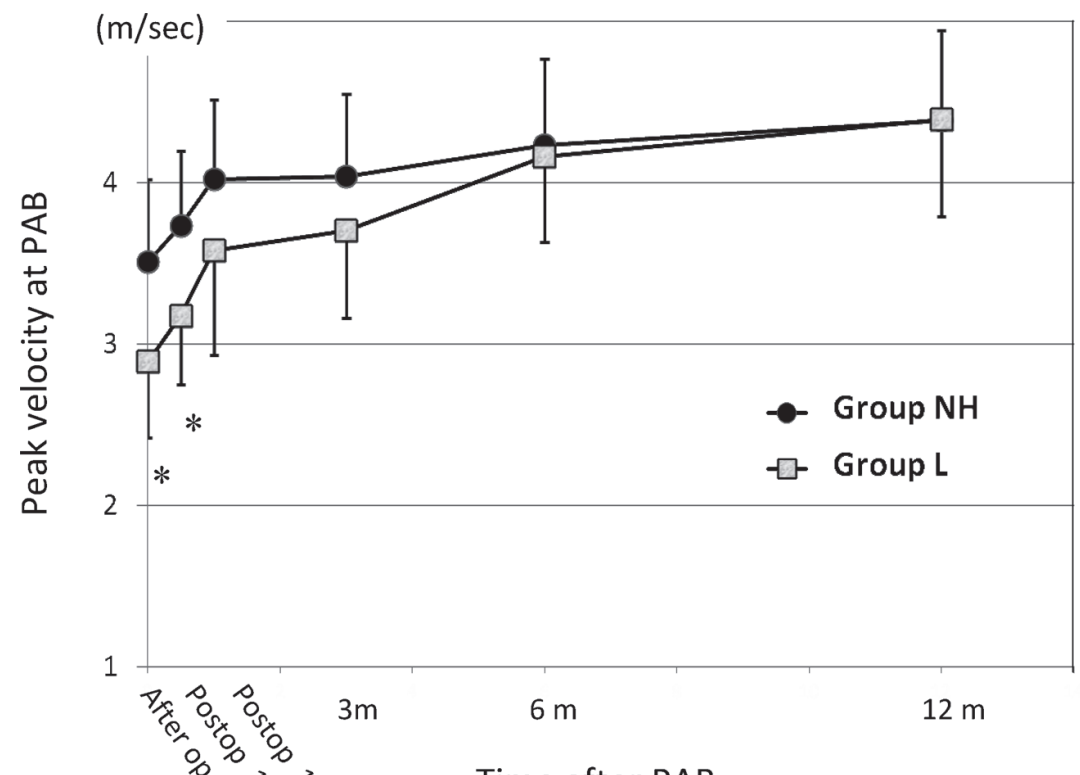

Time after $P A B$

Fig. 3. Time course of the PV at the site of PAB as measured by transthoracic echocardiography after PAB. The black circles represent group $\mathrm{NH}$, and the gray squares represent group L. ${ }^{*} p<0.05$, Group L vs. Group NH.

$\mathrm{PAB}$, pulmonary artery banding; PV, peak velocity.

in group $\mathrm{NH}, p<0.05$ ). However, the $\mathrm{PV}$ in the 2 groups was not significantly different at 1 month after PAB and was equivalent at 6 and 12 months after PAB (Fig. 3).

\section{Increases in $B W$ after $P A B$}

BW continuously increased with age in both groups. Although the observed BW was significantly $(p<0.05)$ lower in group $\mathrm{L}$ during the time course, the proportion of the increase in $\mathrm{BW}$ after PAB was similar in both groups. In group $\mathrm{NH}, \mathrm{BW}$ relative to normal weight was the lowest at 1 month after $\mathrm{PAB}$, and $\mathrm{BW}$ increased thereafter. Conversely, in group L, BW relative to normal weight decreased until 3 months after PAB and increased thereafter (Fig. 4). The average BW at the time of ICR was $7.4 \pm 2.4$ $\mathrm{kg}$ in group $\mathrm{L}$ and $7.9 \pm 2.4 \mathrm{~kg}$ in group $\mathrm{NH}$ (Table 3).

\section{Discussion}

The present study assessed PAB in acyanotic early infants and neonates with low BWs who were candidates for future biventricular repair. $\mathrm{PAB}$ with a circumference of $(19 \mathrm{~mm}+1 \mathrm{~mm}$ for each $\mathrm{kg}$ of BW) had an acceptably low mortality rate. It also led to stable hemodynamics and increased BW with similar proportional rates in patients with low, normal, or high BW at the time of banding. ICR could be safely performed approximately 1-1.5 years after $\mathrm{PAB}$ in most patients weighing at least $7-8 \mathrm{~kg}$, regardless of their BW at the time of PAB.

The intraoperative criteria for adequate PAB vary among institutions. The distal PA pressure between 30\% and $50 \%$ of systemic pressure and the distal systolic PA 

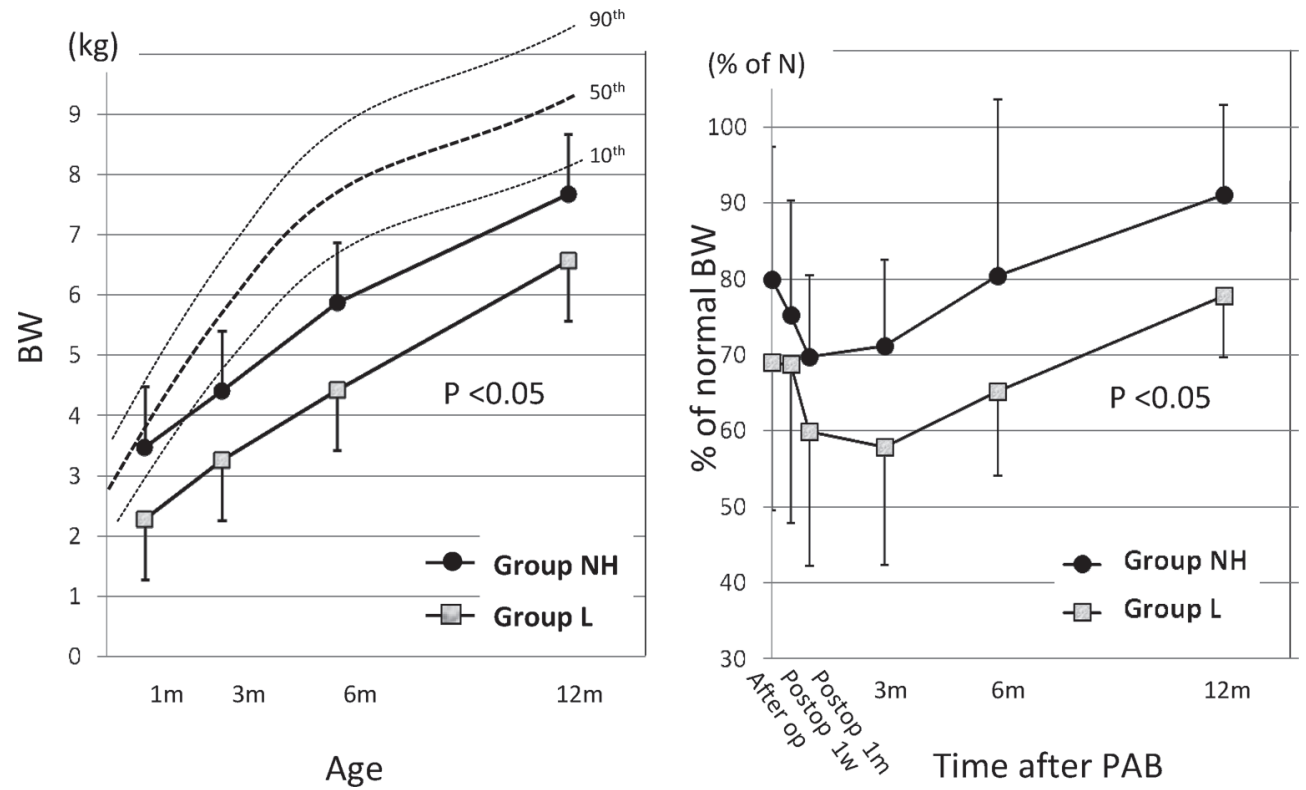

Fig. 4. Left: The relationship between age and BW. Right: Time course of BW expressed as percent of the normal value after PAB. The black circles represent group $\mathrm{NH}$, and the gray squares represent group L. The bold dashed line indicates the $50^{\text {th }}$ percentile of normal BW according to age in Japanese male infants. The fine dashed lines indicate $10^{\text {th }}$ and $90^{\text {th }}$ percentiles of normal BW according to age in Japanese male infants.

$\mathrm{BW}$, body weight; PAB, pulmonary artery banding.

pressure below $30 \mathrm{~mm} \mathrm{Hg}$ have been used as proper hemodynamics parameters (LeBlanc et al. 1987; Van Nooten et al. 1989; Pinho et al. 1997; Takayama et al. 2002). An alternative determining condition is the reduction of the mitral valve flow velocity by $50-70 \%$ compared with the rate before $\mathrm{PAB}$ as measured by echocardiography (Miyamura et al. 1994). However, these intraoperative parameters may not ensure the adequacy of PAB. Kawahira et al. (1995) reported that the intraoperative systolic PA pressure and the systemic arterial oxygen saturation after PAB were not different between patients with good outcomes and those who had residual large pulmonary flow and subsequently required radical operation. The material, width, thickness, and site of the banding tape may have an effect on the pulmonary flow. In addition, a tiny change in the circumference of the banding tape has a considerable effect on the pulmonary flow. Many variable and unstable factors, such as inspired oxygen fraction, arterial partial pressure of carbon dioxide, blood $\mathrm{pH}$, preoperative state of lung congestion, ventricular contractility, and the approach used for PAB (median sternotomy or lateral thoracotomy) also influence the vascular resistance and blood flow in pulmonary circulation.

Trusler and Mustard (1972) advocated that an adequate circumference for PAB in infants with VSDs without mixed disorders was $20 \mathrm{~mm}+1 \mathrm{~mm}$ for each kilogram of BW. This formula has been widely accepted by many institutions (Takayama et al. 2002; Baslaim 2009). On the basis of their clinical findings, their group later stated that the band should be approximately $1 \mathrm{~mm}$ tighter in infants weighing 2 $\mathrm{kg}$ or less (Albus et al. 1984). Kawahira et al. (1995) argued that Trusler's formula is not appropriate for patients weighing less than $3 \mathrm{~kg}$ because the normal pulmonary valve dimension grows exponentially, not linearly. They recommended that the proper banding circumference should be $90 \%$ of the normal standard pulmonary valve-ring circumference. For example, according to their theory, a patient weighing $2 \mathrm{~kg}$ requires a band circumference of approximately $20 \mathrm{~mm}(18 \mathrm{~mm}+1 \mathrm{~mm}$ for each $\mathrm{kg}$ of BW), and a patient weighing $1.5 \mathrm{~kg}$ requires a band circumference of approximately $18 \mathrm{~mm}(16.5 \mathrm{~mm}+1 \mathrm{~mm}$ for each $\mathrm{kg}$ of BW). In our institution, we routinely used a $3-\mathrm{mm}-$ wide tape instead of a 4-mm-wide tape because the average $\mathrm{BW}$ in our series was lower than that reported previously, and a wider tape may increase the possibility of distal PA distortion in small neonates and infants. If the width of the banding tape is decreased from 4 to $3 \mathrm{~mm}$, then the radius of the PAB should be the fourth root of $3 / 4\left((3 / 4)^{1 / 4}=\right.$ 0.9306) according to the Hagen-Poiseuille equation to obtain the same pressure gradient at PAB. Therefore, if the $\mathrm{BW}$ of the patients is $3 \mathrm{~kg}$, then the appropriate circumference of the PAB should be $(18.40 \mathrm{~mm}+1 \mathrm{~mm}$ for each $\mathrm{kg}$ of $\mathrm{BW}$ ), and if the $\mathrm{BW}$ of the patients is $2 \mathrm{~kg}$, then the appropriate circumference of the PAB should be $(18.47 \mathrm{~mm}$ $+1 \mathrm{~mm}$ for each $\mathrm{kg}$ of $\mathrm{BW}$ ). However, this theoretical value is too small and tight to obtain adequate distal pulmonary flow. One of the reasons is that this equation only applies to Newtonian fluids (blood is not a Newtonian fluid) and laminar and continuous flow (pulsatile flow in a setting of $\mathrm{PAB}$ ). The other reason is that the PA wall protrudes inwardly at the several points after PAB because the main PA is usually banded to $50-70 \%$ of the preoperative value. 
Consequently, the sectional area is much smaller than the theoretical value. Thus, in the setting of PAB with the narrower tape, a larger circumference is required compared with the theoretical value.

The required conditions for adequate PAB in the early postoperative period are hemodynamic stability, improvements of heart failure symptoms, and the maintenance of proper oxygen saturation. Conversely, one of the required conditions for adequate $\mathrm{PAB}$ in the late phase is reasonable postoperative BW gain. Van Nooten et al. (1989) reported that the average BW was $9.4 \mathrm{~kg}$ and that the average age was 22 months at the time of ICR in patients who initially underwent PAB. These children still had lower BWs than normal healthy children. In our study, the overall average BW of $7.7 \mathrm{~kg}$ and average age of 18 months at the time of ICR were similar to the findings of Van Nooten. No study has compared the effect of initial PAB followed by ICR 1-1.5 years later with that of only initial ICR on the postoperative somatic growth. Weintraub and Menahem (1991) measured the postoperative somatic growth of patients with VSD who underwent ICR at an average age of 4 months. Twelve months after ICR, the mean z-score for the BW of patients with normal birth weights was -0.5 , which was marginally subnormal. In contrast, at the same time point, the mean $\mathrm{z}$-score for the BW of patients with low birth weights remained depressed at -2.0 . These data were very similar to our findings for patients who underwent PAB. Twelve months after PAB, the BW of group $\mathrm{NH}$ patients was in the $20^{\text {th }}$ to $50^{\text {th }}$ percentile of healthy children, whereas in group L patients, BW remained below the $1^{\text {st }}$ percentile. That is, neither ICR nor PAB allowed patients with low $\mathrm{BW}$ at the time of PAB to achieve a normal $\mathrm{BW}$ at 12 months after surgery. The limited growth potential of this group may be related to the fact that many patients present with other pathological conditions such as congenital gastrointestinal disorders or genetic anomalies.

In this report, the patterns of $\mathrm{BW}$ gain and percentnormalized BW after PAB in group L were very similar to those in group $\mathrm{NH}$. However, $\mathrm{BW}$ and percent-normalized BW in group L did not reach the same level as that for group NH. A significant but slightly lower pressure gradient shortly after PAB in group L may have delayed the recovery of $\mathrm{BW}$ in this period. However, tighter banding may lead to oxygen desaturation shortly after PAB, resulting in the need for early ICR in patients with low BW.

According to several studies (LeBlanc et al. 1987; Van Nooten et al. 1989; Yoshimura et al. 2005; Ohashi et al. 2006; Baslaim et al. 2009), the average interval between PAB and ICR varied from 12.4 to 34.8 months. However, no report has elucidated the optimal timing for ICR after PAB. In our institution, ICR is considered if the BW of the patients exceeds 6-8 $\mathrm{kg}$ because the operation can be performed without blood transfusion at these BWs.

Peripheral pulmonary stenosis, especially on the right side, after PAB was mentioned in some studies (Robertson et al. 1991; Hiraishi et al. 1995). This complication may increase the operative risk at the time of ICR. Robertson et al. (1991) described that the right PA arises more proximally at a more acute angle from the main PA than the left PA, which might have caused the right side PA stenosis. Another reason for this complication may be that it was difficult to place the stitch to prevent dislocation on the right side of the right PA in the left thoracotomy approach. In our study, $44 \%$ of patients underwent angioplasty of the peripheral PA at the time of ICR. However, proactive enlargement of the peripheral PA was performed whenever surgeons suspected a small possibility of peripheral PA narrowing even without a pressure gradient. In fact, only $19 \%$ of patients had a pressure gradient of more than $5 \mathrm{~mm} \mathrm{Hg}$ between the right and left peripheral PAs. This incidence rate was consistent with that reported by Robertson et al. (1991).

In conclusion, $\mathrm{PAB}$ with a circumference of $(19 \mathrm{~mm}+$ $1 \mathrm{~mm}$ for each $\mathrm{kg}$ of BW) using a $3 \mathrm{~mm}$ wide tape led to good hemodynamic stability and BW gain even in patients weighing less than $2.5 \mathrm{~kg}$ at the time of $\mathrm{PAB}$, although several patients required very subtle but appropriate banding adjustments. Although patients weighing less than $2.5 \mathrm{~kg}$ had still lower BW after PAB, ICR could be safely performed in these patients with an average age of 1.5 years and an average BW of $7.4 \mathrm{~kg}$. PAB even in the acyanotic neonates and early infants with low BW has a low mortality rate with low morbidity and is safe and effective as a bridge to ICR.

\section{Conflict of Interest}

The authors have no conflict of interest to declare in relation to this article.

\section{References}

Albus, R.A., Trusler, G.A., Izukawa, T. \& Williams, W.G. (1984) Pulmonary artery banding. J. Thorac. Cardiovasc. Surg., 88, 645-653.

Baslaim, G. (2009) Modification of Trusler's formula for the pulmonary artery banding. Heart Lung Circ., 18, 353-357.

Hiraishi, S., Misawa, H., Agata, Y., Hirota, H., Horiguchi, Y., Fujino, N., Takeda, N., Nakae, S. \& Kawada, M. (1995) Obstruction of the proximal pulmonary artery branches after banding of the pulmonary trunk. Am. J. Cardiol., 76, 842-846.

Kawahira, Y., Kishimoto, H., Kawata, H., Ikawa, S., Ueda, H., Ueno, T., Nakajima, T., Kayatani, F., Inamura, N. \& Miwatani, T. (1995) Optimal degree of pulmonary artery bandingadequate circumference ratio to calculated size from normal pulmonary valve dimensions. Am. J. Cardiol., 76, 979-982.

Kuroki, Y. (1985) Body development pattern. In Pediatrics MOOK No. 38 Down syndrome, 1st ed., edited by Baba, K., Kobayashi, N. \& Kuroki, Y. Kanehara \& CO, Tokyo, Japan. 93-107.

LeBlanc, J.G., Ashmore, P.G., Pineda, E., Sandor, G.G., Patterson, M.W. \& Tipple, M. (1987) Pulmonary artery banding: results and current indications in pediatric cardiac surgery. Ann. Thorac. Surg., 44, 628-632.

Miyamura, H., Watanabe, H., Sugawara, M., Tatebe, S., Hayashi, J., Eguchi, S. \& Sato, I. (1994) Adjustment of pulmonary artery banding by mitral valve flow velocity. Cardiovasc. Surg., 2, 384-386.

Ohashi, N., Matsushima, M., Maeda, M. \& Yamaki, S. (2006) 
Two-stage procedure for pulmonary vascular obstruction disease in Down syndrome with congenital heart disease. Circ. J., 70, 1446-1450.

Oppido, G., Pace Napoleone, C., Formigari, R., Gabbieri, D., Pacini, D., Frascaroli, G. \& Gargiulo, G. (2004) Outcome of cardiac surgery in low birth weight and premature infants. Eur. J. Cardiothorac. Surg., 26, 44-53.

Pinho, P., Von Oppell, U.O., Brink, J. \& Hewitson, J. (1997) Pulmonary artery banding: adequacy and long-term outcome. Eur. J. Cardiothorac. Surg., 11, 105-111.

Robertson, M.A., Penkoske, P.A. \& Duncan, N.F. (1991) Right pulmonary artery obstruction after pulmonary artery banding. Ann. Thorac. Surg., 51, 73-75.

Takayama, H., Sekiguchi, A., Chikada, M., Noma, M., Ishizawa, A. \& Takamoto, S. (2002) Mortality of pulmonary artery banding in the current era: recent mortality of PAB. Ann. Thorac.
Surg., 74, 1219-1223.

Trusler, G.A. \& Mustard, W.T. (1972) A method of banding the pulmonary artery for large isolated ventricular septal defect with and without transposition of the great arteries. Ann. Thorac. Surg., 13, 351-355.

Van Nooten, G., Deuvaert, F.E., De Paepe, J. \& Primo, G. (1989) Pulmonary artery banding. Experience with 69 patients. $J$. Cardiovasc. Surg., 30, 334-337.

Yoshimura, N., Yamaguchi, M., Oka, S., Yoshida, M. \& Murakami, H. (2005) Pulmonary artery banding still has an important role in the treatment of congenital heart disease. Ann. Thorac. Surg., 79, 1463.

Weintraub, R.G. \& Menahem, S. (1991) Early surgical closure of a large ventricular septal defect: influence on long-term growth. J. Am. Coll. Cardiol., 18, 552-558. 